\title{
THE JAKARTA TOD MODEL APPLICATION FOR TYPOLOGY OF MIDDLE CITIES (APPLIED RESEARCH DESIGN IN KUPANG CITY)
}

\author{
Kusa Bill Noni NOPE ${ }^{1}$, Putu Alit SUTHANAYA ${ }^{1}$, Dewa Made Priyantha WEDAGAMA ${ }^{1}$, \\ I. Nyoman Yudha ASTANA ${ }^{1}$
}

DOI: 10.21163/GT_2020.151.27

\begin{abstract}
:
Realizing the vision of sustainable cities in Indonesia is a necessity. The Indonesian government continues to encourage all parties making various approaches to solving the urban problems to create a livable city in 2045. The TOD is widely recognized by researchers as one of the most feasible and comprehensive sustainable planning approaches. In Indonesia, only Jakarta has begun implementing TOD since 2017. This study aims to obtain respondents' perceptions (government, business actors, and experts) to assess the alignment of the Jakarta TOD Model compared with the key success factor of TOD best practice, also in line with the principles of urban transportation sustainable development. This analysis is quantitative descriptive for hypothesis testing uses non-parametric statistical tests: Independent and Bayesian One-Sample T-Test. The results of the analysis show us that the Jakarta TOD Application Model is not in line yet with the principles of urban and transportation sustainable development. This is caused by several factors of Bayes interpretation. Refers to the result of variable Large Bayes effect analysis (based on Cohen's value d), its need to be re-arrangement some regulations and/or policies by considering: an institutional improvement, integrated planning, definition of TOD, partnership patterns, development strategy, sustainable and inclusive development goals.
\end{abstract}

Key-words: Urban Sustainable, Sustainable Transportation, TOD, Independent and Bayesian One-Sample T-Test

\section{INTRODUCTION}

The Government of the Republic of Indonesia, through the Ministry of National Development Planning/NDPA, had been formulated a National Urban Policy Framework and disseminated in October 2018, establishing the Indonesian Urban Vision is "Sustainable Cities 2045: Inclusive, Prosperous, Green and Resilient" (Ministry of National Development Planning, 2018). Various results of the literature review from the perspective of transportation, the experts stated that almost all major cities around the world currently are developing urban transportation systems through the Transit-Oriented Development (TOD) concept approach, as a part of the implementation of sustainable cities. The main issue is a compact city, by prioritizing the public transportation and walking or cycling transportation systems as the backbone.

The rapid rate of uncontrolled urbanization has caused cities to continue to develop dynamically and sometimes develop uncontrollably (sprawl), especially urban areas in

\footnotetext{
${ }^{1}$ Udayana University, Civil Engineering Department, 80234, Denpasar Indonesia, kusanope.pnk@gmail.com; suthanaya@rocketmail.com; priyantha@civil.unud.ac.id; astana_yudha@yahoo.com
} 
developing countries. Besides urbanization, urban sprawl has positive and negative impacts for a citizen, as well as the economy, culture, and environment, clean water, transportation needs, food security, energy, etc. This gives the impression of a city that is chaotic (slum) and not livable (Giduthuri, 2015). Urbanism raises issues of land use, transportation, and the urban environment (Motieyan and Mesgari, 2017). In developing countries, the population density of urban areas will increase if it's close to the location of economic activity, which is the city center and will decrease when it's far from the city center (Malik, Suparta and Dewancker, 2019).

To overcome this problem, urban planners apply a planning approach in an integrated and integrated manner and are more compatible with the goals of sustainable development. Urban planners agree that the challenges of urban development are an urgent need to achieve sustainable development goals. The most basic thing is that it requires the active participation and involvement of the local urban population. However, the approach is complex and multidimensional. Intensive collaborative research between urban planners, architects, designers and infrastructure managers is needed to produce a concept and outcome of sustainable urban development comprehensively (Kabisch, 2019). One proof that active community participation is a key success factor in creating and developing dense urban areas that are when developing a dense old city through sustainable urban landscape approaches such as Kembang Jepun in Surabaya (Soemardiono et al., 2019)

Discussing urban development, the national and regional levels of governments must be directed to improve the quality of public transportation services due to the high use of private vehicles in urban areas (Wei and Ewing, 2018). The development of transportation infrastructure cannot be separated from the consumption of land use, impacts on environmental damage, and social dislocation (Bagheri and Tousi, 2018). The process should be starting from re-evaluating the factors and sustainability key performance of each transport infrastructure project and reviewing the framework of the relationship between sustainable development factors and the performance of infrastructure projects (Amiril et al., 2014). Therefore, the government needs to make serious efforts in applying the concept of sustainable transportation development as an important factor, and also serious for promoting the implementation of sustainable development strategies in the field of transportation, especially in urban areas.

The Transit-Oriented Development (TOD) approach is widely recognized by researchers as one of the most feasible and comprehensive sustainable planning approaches (Motieyan and Mesgari, 2017). The results of a review of several kinds of literatures are known that most modern and developed cities in the world today are starting to apply the TOD Model as one of the appropriate transportation management approaches in implementing traffic demand management. In the context of sustainable cities, TOD approaches were able to increase mobility and expedite traffic (Guerra et al., 2018), but must be supported by structuring the city structure and the pattern of the use of urban and/or regional spatial layout properly (Liu et al., 2018). The application of TOD in various regions still has many very striking gaps because each region has different natural characteristics, social, economic, cultural, and environmental factors. However, all experts agree that the principle of sustainable transportation intervened through the TOD approach can reduce private car dependency (Akbari et al., 2018).

Some research result show that the application of TOD still reaps various challenge factors in various countries, including (1) factors of socio-cultural characteristics of the community of urban areas; (2) political and local government policies, especially noncompliance in implementing regulations, including the potential for high personal and group 
interests and policies that tend to be ego-sectorial, other than because of political conflicts therein; (3) land ownership is also potentially hamper the application of TOD due to multiplechoice, disputed land, land brokerage, uncontrolled selling prices; (4) the distance of settlements and transit points in high-temperature coastal areas results in people reluctant to walk; (5) the availability of on-line transportation modes is increasingly prevalent in doorto-door service, caused people just wait to be picked up and/or delivered (Thomas et al., 2018 ; Thomas, Rao and Sohoni, 2017 ; Pan et al., 2017), etc. Based on this, it's necessary to consider implementing TOD Model in other cities in Indonesia.

\section{STUDY AREA AND DATA}

In Indonesia, only one Regional Government that already has Regulations on the application of TOD, it is the Provincial Government of DKI Jakarta. This is stated in DKI Jakarta Governor Regulation Number 44 the Year 2017 about Development of Transit Oriented Development Areas and then revised through the DKI Jakarta Governor Regulation Number 67 the Year 2019 about the Implementation of Transit-Oriented Areas. The Jakarta TOD Model had been applied in Palembang City but is not optimal yet. Some questions arise, why has the Jakarta TOD Model failed to be implemented in Palembang City? Did the Jakarta TOD Model in line with TOD best practices and relevant to the concept of sustainable city development? This is the driving force for this research.

Jakarta, as the capital of the Republic of Indonesia, is developing very rapidly. The number of private transportations in Jakarta is more than 18.6 million vehicles. Public transport users in Jakarta only reach $24 \%$. The number of movements in Jabodetabek is around 47.5 million. The Jakarta Central Bureau of Statistics (BPS) data Year 2015 shows that every day there are around 1.4 million commuters from the area around the Capital City. The rapid and uncontrolled trend of expansion in the Jakarta-Bodetabek area has significantly increased transportation costs, reduced the level of mobility, and reduced the quality of life of its residents.

The rapid and uncontrolled development of the cities of Jakarta and Bodetabek is largely due to the construction of low-floor settlements (almost $64 \%$ of the total Jakarta area) and low-rise buildings cause high land consumption in Jakarta. As a result, Jakarta currently does not have enough space for future development. Now, it's time for Jakarta to change its development paradigm, no longer oriented to the use of private vehicles (especially cars), but rather to pedestrians and mass public vehicles. These changes not only stop at providing an adequate mass transportation system but also the concept of urban development which must provide convenience and comfort for its inhabitants, including regional staging, passenger flow, and intermodal integration.

TOD is an urban area that is designed to integrate transit functions with humans, activities, buildings, and public spaces that aim to optimize access to public transportation so that it can support the carrying capacity of the passenger. The issue of the city of Jakarta is what drives PT MRT Jakarta to develop the concept of transit-oriented or transit-oriented development (TOD) in several stations, for phase 1 is the South-North corridor of 13 TOD Areas (Fig.1). 


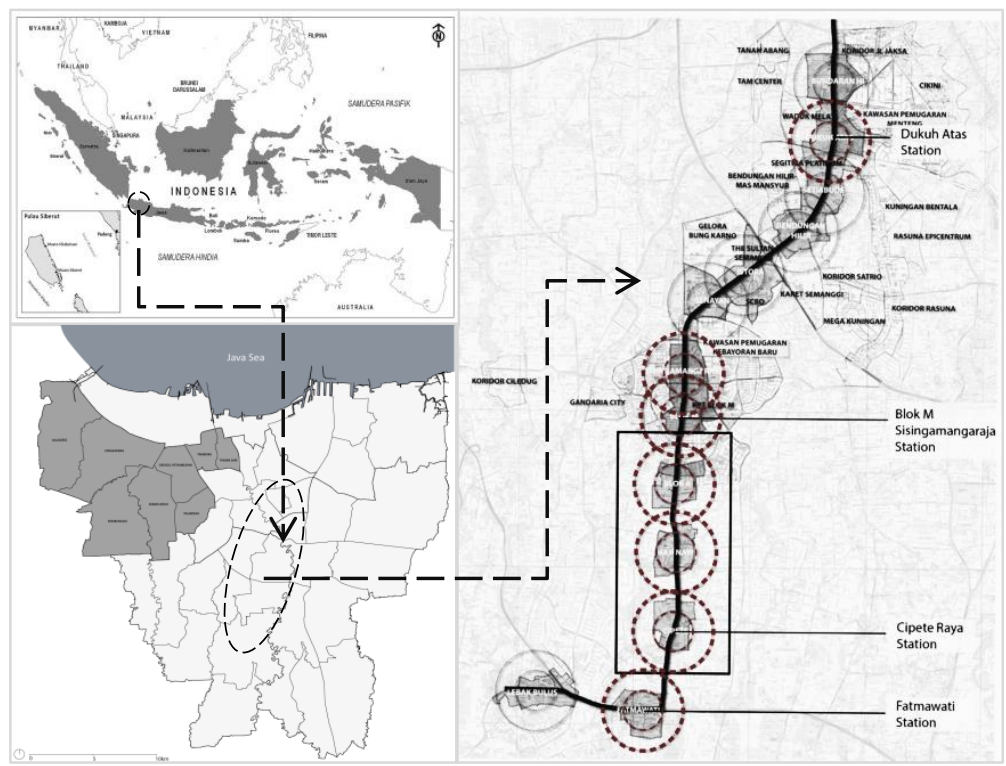

Fig.1. Indonesian countries and Jakarta City (left) and Jakarta TOD Model (right). (Source: https://www.jakartamrt.co.id/konektivitas/transit-oriented-development-tod/).

As additional information, the existing condition of most cities in Indonesia indicates the low standard of urban services. The indicators are many urban slums, drinking water, and poor sanitation services, high urbanization, increased use of private vehicles, low urban public transport services, the environmental carrying capacity of urban areas are decreasing. This is profaning that the development of cities in Indonesia has not pointed yet to the concept of sustainable cities. Studied from the Jakarta TOD Model, the authors are interested to conduct an applied research TOD model for a typology of medium cities that has the potential to develop into a large city or metropolitan city. This is important because the analysis of NDPA in 2018 predicts that in 2050 a total number of 13 cities in Indonesia will change from the typology of medium cities to metropolitan cities, one of them is Kupang City. Also, cities in Indonesia will be dominated by cities with the typology of the medium city as much as $62 \%$.

\section{METHODOLOGY}

First of all, it needs to be understood that this study aims to obtain respondents' perceptions (by the government, business actors, and experts) to assess the alignment of the Jakarta TOD Model Application compared by the key success variables or best practice of TOD implementation. Based on the results of literature reviews, seminars, and forum group discussion, we summarized there are have 8 key variables (latent variables) of the best practice of TOD principle's that are: (1) definition of TOD, (2) location suitability, (3) development strategy, (4) integrated plans, (5) institutional, (6) partnerships, (7) inclusive goals, and (8) sustainable development.

Perceptual assessment for the Jakarta TOD Model application is done through hypothesis testing uses non-parametric statistical tests, which is: 
$\mathrm{H}_{0}=$ if the Jakarta TOD Model Application is in line with the principle of urban and transportation sustainable development

$\mathrm{H}_{1}=$ if the Jakarta TOD Model Application is not in line yet with the principle of urban and transportation sustainable development

given that amount of data $\mathrm{N}<30$, the hypothesis formula, used are:

$$
\begin{aligned}
& \mathrm{H}_{0}=\text { accepted if }-\mathrm{t}_{\mathrm{a} / 2} \leq \mathrm{t}_{\mathrm{o}} \leq \mathrm{t}_{\mathrm{a} / 2} \\
& \mathrm{H}_{1}=\text { accepted if }-\mathrm{t}_{0}<-\mathrm{t}_{\mathrm{a} / 2} \text { or } \mathrm{t}_{0}>\mathrm{t}_{\mathrm{a} / 2}
\end{aligned}
$$

for conditions where $\mathrm{H}_{0}: \mu_{1}=\mu_{2}$ and $\mathrm{H}_{1}: \mu_{1} \neq \mu_{2}$

Furthermore, for measuring variables empirically (observed variables) or indicators using discrete variables as a result of respondents' perceptions of the questions outlined in the questioner then given a value based on a Likert scale of 1 to 5 for each question. Respondents' answers are chosen number 5 if the respondent considers that the Jakarta TOD implementation model is very compatible with the key to success or best practice of TOD implementation. Respectively, the respondents choose number 4 if it regards appropriate, number 3 if it is not appropriate, number 2 if not suitable, and number 1 is considered very incompatible with the key variables for successful TOD implementation. This research method is explained briefly through the scheme as shown in Fig.2.

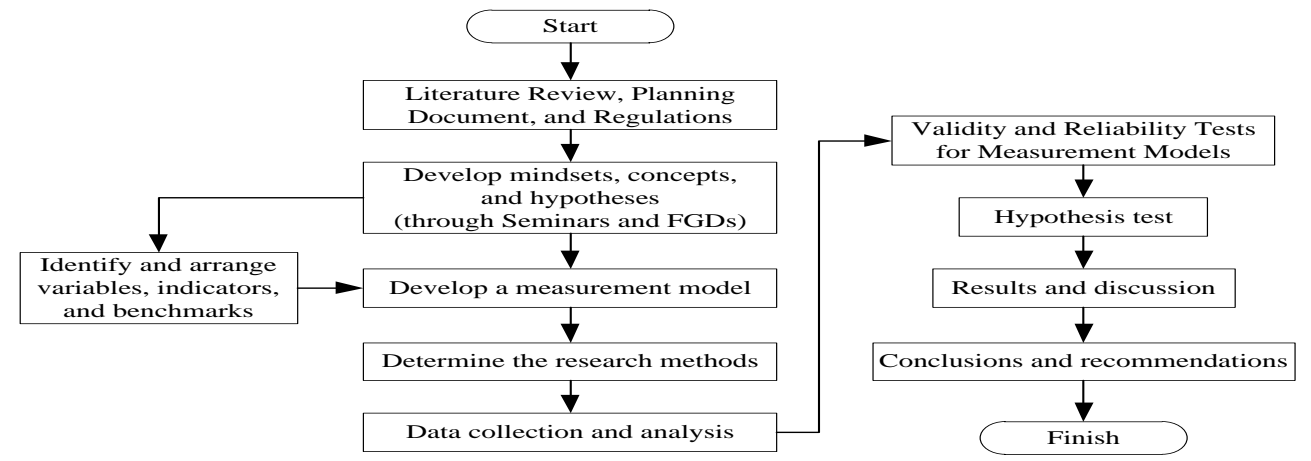

Fig. 2. Flowchart of Research Methodology.

The data collection process is done through the distribution of questionnaires to three parties where they are considered to have direct interests and understanding of the application of TOD. The respondents participating parties are elements of government (10 persons), business actors (10 persons), and experts (10 persons). Here, expert judgment is considered because it is a neutral party (counterweight) in providing perception. Therefore, at the end of the perception assessment need to see also the dynamic force flow between the respondent variables through the inferential analysis presented by form of descriptive plots. The data obtained were then analyzed to answer the research objectives. As for some of the tests conducted, that is: (1) Descriptive statistical tests to obtain temporary answers to research hypotheses; (2) Test the validity and reliability using the values of McDonald's $\omega$, Guttmann's $\lambda$ i, and Cronbach's $\alpha$; (3) Test classic assumptions using the Test of Normality using Shapiro-Wilk based on W and P-value; (4) Hypothesis testing using Independent OneSample T-Test given by t value, p-value, effect size Cohen's d; and (5) To interpret how far the degree of subjective trust must change rationally when new guidelines or policies are using Bayesian One-Sample T-Test Log (BF), Density f (x| $\mid \theta)$, Prior $\pi(\theta)$, and Posterior $\pi$ $(\theta \mid \underline{X})$ analysis. Software used for statistical data analysis using JASP Computer software by JASP Team (2018) with JASP Version 0.9.2. 


\section{RESULT AND DISCUSSION}

The initial stage of data analysis in this study starts from the reliability test to see the consistency of responses to the perception of variables. The reliability test result using parameter value uses the Guttmann's scale value $\lambda 6=0.847$; McDonald's $\omega$ based on Structural Equation Model $(\mathrm{SEM})=0.809$, and Cronbach's $\alpha=0.795$ shows that overall scales value $>0.6$. This meaning that the respondents' answers are consistent (Table 1).

Data reliability test results.

Table 1.

\begin{tabular}{|l|c|c|c|c|}
\hline \multicolumn{5}{|c|}{ Descriptive Statistics } \\
\hline \multicolumn{1}{|c|}{ Latent Variable } & N & Mean & Standard Dev. & Standard Error \\
\hline Definition of TOD & 29 & 2.759 & 0.636 & 0.118 \\
\hline Location Suitability & 29 & 2.138 & 0.581 & 0.108 \\
\hline Development Strategy & 29 & 2.724 & 0.702 & 0.130 \\
\hline Integrated Plans & 29 & 2.897 & 0.673 & 0.125 \\
\hline Institutional & 29 & 3.414 & 0.983 & 0.182 \\
\hline Partnership & 29 & 3.000 & 0.964 & 0.179 \\
\hline Inclusive Goals & 29 & 2.690 & 1.105 & 0.205 \\
\hline Sustainable Development & 29 & 2.621 & 0.903 & 0.168 \\
\hline \multicolumn{5}{|c|}{ Reliability Statistics } \\
\hline \multicolumn{7}{|c|}{ Basis SEM } & Mean & SD & McDonald's $\mathbf{~}$ & Cronbach's $\boldsymbol{\alpha}$ \\
\hline \multicolumn{7}{|c|}{ Scale } & 2.78 & 0.361 & 0.809 & 0.795 \\
\hline $\begin{array}{l}\text { Note: Of the observations, 29 were used, 0 were excluded list wise, and 29 were provided consistency } \\
\text { respondent if value reliability scale > 0.6; Guttmann's } \lambda 6=0.847\end{array}$ \\
\hline
\end{tabular}

Next, the normality test was done using The Shapiro-Wilks test. The Shapiro-Wilks test for normality is one of three general normality tests designed to detect all departures from normality. It is comparable in power to the other two tests. The test rejects the hypothesis of normality when the $\mathrm{p}$-value $\leq 0.05$, and sig-value (significance value or Pvalue) $>0.05$, then the data are declared normal distribution. Normality test results (Table 2) show that the data are not normally distributed because of the $P$-value $<0.05$, the distribution is skew. For this reason, further data testing uses non-parametric statistics.

Table 2.

Test of Normality (Shapiro-Wilk) result.

\begin{tabular}{|l|c|c|}
\hline \multicolumn{1}{|c|}{ Latent Variable } & W & p \\
\hline Definition of TOD & 0.776 & $<.001$ \\
\hline Location Suitability & 0.748 & $<.001$ \\
\hline Development Strategy & 0.786 & $<.001$ \\
\hline Integrated Plans & 0.798 & $<.001$ \\
\hline Institutional & 0.874 & 0.002 \\
\hline Partnership & 0.830 & $<.001$ \\
\hline Inclusive Goals & 0.852 & $<.001$ \\
\hline Sustainable Development & 0.882 & 0.004 \\
\hline Note: Significant results suggest a deviation from normality. \\
\hline
\end{tabular}

The next step is to test the hypothesis. This research uses non-parametric hypothesis testing. Since the scale of ordinal data and the nature of the distribution are skewed, some hypothetical testing options that can be done are: for example, replacing the T-Test with 
Man-Whitney or Kruskal, Anova with Kruskal, Paired T-Test with One-Sample Sign Test, and other non-parametric tests. This study chose to use the Independent One-Simple Sign Test, and the results are presented in Table 3 .

Independent One Sample T-Test result.

Table 3.

\begin{tabular}{|c|c|c|c|c|c|c|}
\hline \multirow{2}{*}{ Latent Variable } & \multirow{2}{*}{$\mathbf{t}$} & \multirow{2}{*}{ df } & \multirow{2}{*}{$\mathbf{p}$} & \multirow{2}{*}{ Cohen's d } & \multicolumn{2}{|c|}{ 95\% CI for Cohen's d } \\
\hline & & & & & Lower & Upper \\
\hline Definition of TOD & 6.021 & 28 & $<.001$ & 1.118 & 0.646 & 1.578 \\
\hline Location Suitability & 0.834 & 28 & 0.412 & 0.155 & -0.213 & 0.520 \\
\hline Development Strategy & 5.188 & 28 & $<.001$ & 0.963 & 0.515 & 1.400 \\
\hline Integrated Plans & 6.788 & 28 & $<.001$ & 1.260 & 0.764 & 1.744 \\
\hline Institutional & 7.485 & 28 & $<.001$ & 1.390 & 0.870 & 1.897 \\
\hline Partnership & 5.320 & 28 & $<.001$ & 0.988 & 0.536 & 1.428 \\
\hline Inclusive Goals & 3.126 & 28 & 0.004 & 0.581 & 0.182 & 0.970 \\
\hline Sustainable Development & 3.416 & 28 & 0.002 & 0.634 & 0.230 & 1.029 \\
\hline
\end{tabular}

To conclude the results of hypothesis test, the interpretation of the test results is done by comparing results of $t$ arithmetic with $t$ table $\left(t_{a / 2}\right)$ and the value of probability ( $p$ value). The assessment parameter used is:

1. Based on $\mathrm{t}$ value:

$\mathrm{H}_{0}=$ accepted if $-\mathrm{t}_{\mathrm{a} / 2} \leq \mathrm{t}_{\mathrm{o}} \leq \mathrm{t}_{\mathrm{a} / 2}$ or in this case is $-2.048 \leq \mathrm{t} \leq 2.048$

$\mathrm{H}_{1}=$ accepted if $-\mathrm{t}_{0}<-\mathrm{t}_{\mathrm{a} / 2}$ or $\mathrm{t}_{0}>\mathrm{t}_{\mathrm{a} / 2}$ or in this case is $-\mathrm{t}<-2.048$ or $\mathrm{t}>2.048$

2. Based on probability using p-value:

$\mathrm{H}_{0}=$ accepted if $\mathrm{p}$-value $>0.05$

$\mathrm{H}_{0}=$ rejected if $\mathrm{p}$-value $<0.05$

Whereas, to find out the level of confidence of the Bayes effect (small $<0.2$, medium $=0.5$, large $>$ 0.8 ) using the parameter value is Cohen $d$.

For this case, the test result show that $t$ value of 7 variables is $>2.048$ (it means that $\mathrm{H} 0$ is rejected), except 1 variable i.e. Location Suitability with $\mathrm{t}$ value $=0.834>-2.048$ and 0.843 $<2.048$ (it means that $\mathrm{HO}$ is accepted). Likewise, based on probability parameters, all test results $\mathrm{P}$-value $<0.05$ (it means $\mathrm{H} 0$ is rejected), except for variable Location Suitability with $\mathrm{P}$-value $=0.412>0.05$ (it means $\mathrm{H} 0$ is accepted). Hence, it can generally state that the Jakarta TOD Model Application is not in line yet with the principle of urban and transportation sustainable development. Bayes effect level refers to the results of the analysis by Cohen's d value showing that the value of Cohen's $d$ is 7 variables $>0.8$ or it can be said that the effect of Bayes is large, except for 1 variable namely Location Suitability with Cohen's d value of $0.155<0.2$ (level of Bayes effect small). From these results, it can be stated that the determination of TOD location is not a major effect variable in the application of TOD in Jakarta. Not yet in line with the Jakarta TOD Implementation Model with the best practice of TOD and Urban Principles and transportation sustainability caused by several factors Bayes interpretation.

Some variable Large Bayes effect (based on Cohen's value $d>0.8$ ) is the institutional variable $(1,390)$, integrated planning $(1,269)$, Definition of TOD $(1,118)$, Partnership (0.988), and Development strategy (0.963). There are two variables categories in the moderate Bayes effect are sustainable development (0.634) and inclusive goals (0.581). 
Table 4.

Bayesian Independent One-Sample T-Test result.

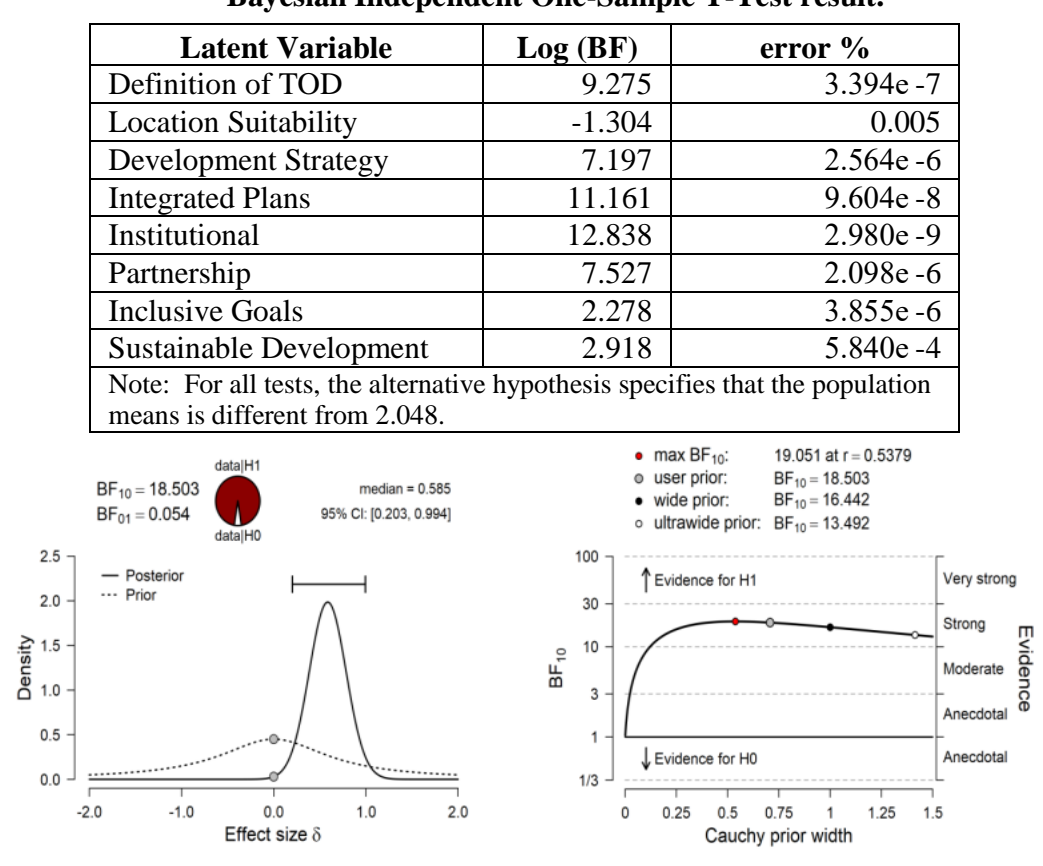

Fig. 3. Prior and posterior Bayes Factor Robustness Check.

One mathematical tool and philosophical approach for modeling uncertainty through prior or model or loss classes, as well as measuring uncertainty and its effects, to avoid arbitrary assumptions, can be done through the Bayesian approach, for example, Bayesian Robustness analysis. The results of the analysis show that psychologically the level of subjective trustworthiness of the respondents towards the current application of the Jakarta TOD Model, refers to result of Bayesian One-Sample T-Test Log $\left(\mathrm{BF}_{10}\right)$, Density f $(\mathrm{x} \mid \theta)$, Prior $\pi(\theta)$, and Posterior $\pi(\theta \mid \underline{X})$ analysis (Table 4 and Fig.2.) tends to be strong towards $\mathrm{H} 1$ or $\mathrm{H} 0$ is rejected. These results also prove that there is a strong suspicion that Jakarta is currently the Jakarta TOD Application Model is not in line yet with the principles of urban and transportation sustainable development.

Learning from the experience of the TOD Model in Jakarta, at this time, the research will be continued by developed a TOD model application to be applied for a typology city, which has the opportunity to develop, to become a typology of a large city and or metropolitan city (even as a megapolitan city). Kupang city was chosen as the object of research because this city is one of the cities that are projected to potentially develop into a big city between 2025, 2035 and 2045 to become a Metropolitan City. The weakness of implementation in Jakarta will be an important lesson when creating models for implementation in Kupang. The research framework will be arranged in the form of the Structural Equation Model that can be collected can be seen in Fig. 4. 


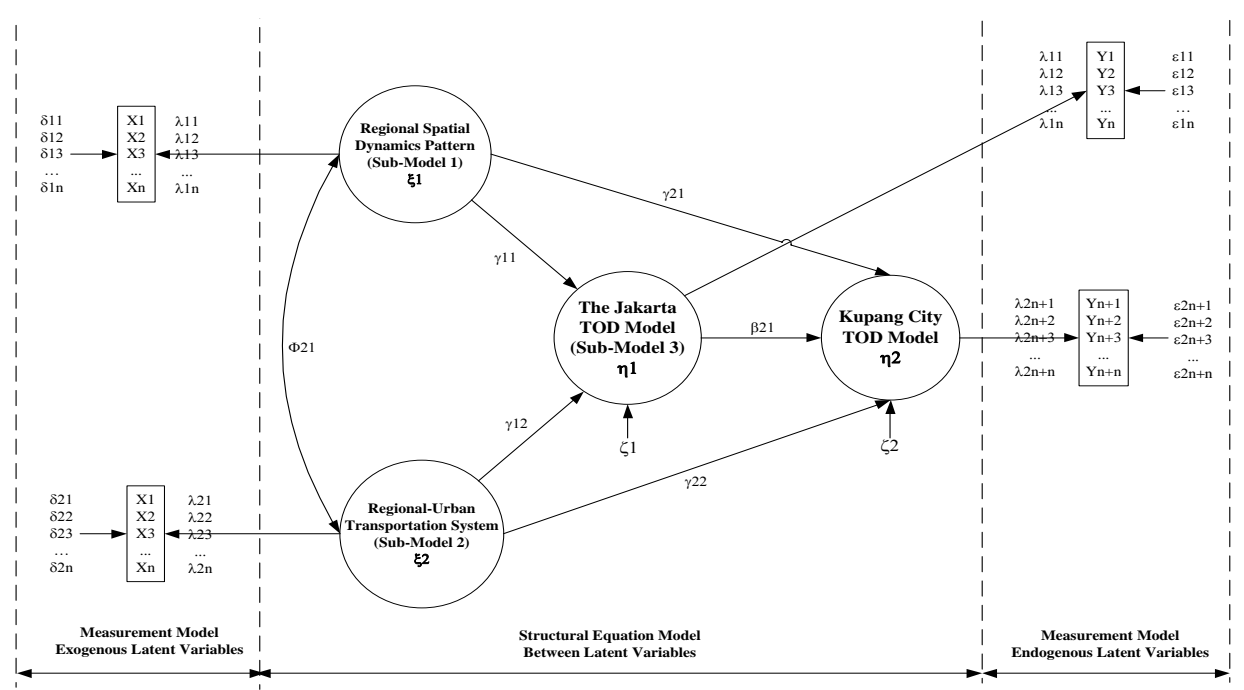

Fig. 4. Causal Relations Diagram of Research Variables.

The structural equation based on the Structure Model Specifications in Fig. $\mathbf{5}$ is written in the form of an equation for analysis as follows:

$$
\begin{aligned}
& \eta=\mathrm{B} *(\eta+\Gamma)(\xi+\zeta) \\
& \mathrm{x}=\Lambda \mathrm{x} *(\xi+\delta) \\
& \mathrm{y}=\Lambda \mathrm{y} *(\eta+\varepsilon)
\end{aligned}
$$

Furthermore, the estimation of the structure model above is done through the choice of estimation method in the SEM domain, namely the Maximum Likelihood (MLE) estimation procedure. Mathematically, the Covariance Model Matrix can be written as follows:

$$
\Sigma \theta=\mathrm{V} *\left[\begin{array}{l}
x \\
y
\end{array}\right]=\mathrm{V} *\left[\begin{array}{cc}
\Lambda \mathrm{x} \Phi \Lambda^{\prime} \mathrm{x}+\Theta \delta & \Lambda \mathrm{x} \Phi \mathrm{M}^{\prime} \Gamma^{\prime} \\
\mathrm{M} \Phi \Lambda^{\prime} \mathrm{x} & \mathrm{M} \Gamma \Phi \Gamma^{\prime} \mathrm{M}^{\prime}+\mathrm{M} \psi \mathrm{M}^{\prime}+\Phi \varepsilon
\end{array}\right]
$$

Where, $\mathrm{M}=\Lambda \mathrm{y} *\left((\mathrm{I}-\mathrm{B})^{-1}\right)$ and testing the null hypothesis (goodness of fit) measured by $\mathrm{H}_{0}: \mathrm{Cov}$ (z) $=\Sigma \theta$ and $\mathrm{H}_{1}: \operatorname{Cov}(\mathrm{z}) \neq \Sigma \theta$.

\section{CONCLUSIONS}

The results of the analysis show us that the Jakarta TOD Application Model is not in line yet with the principles of urban and transportation sustainable development caused by several factors Bayes interpretation when correlated with the principles of the Jakarta TOD Model application. Refers to result of some variable Large Bayes effect analysis (based on Cohen's value d), its need to be re-arrangement some regulations and/or policies by considering some important variables, that is: institutional improvement, integrated planning, definition of TOD, strong partnership patterns (government, business entities, and communities), and future development strategy. Also, important to consider two variables categories in the moderate Bayes effect are sustainable and inclusive development and goals. 


\section{ACKNOWLEDGMENT}

The researcher would like to thank the DKI Jakarta government, business entities, and experts who have provided time, critics, suggestions, in every internal discussion, both directly and indirectly. Any deficiencies in this research are the responsibility of the author.

\section{R E F E R E N C E S}

Akbari, S. et al. (2018) Empirical models of transit demand with walk access/egress for planning transit oriented developments around commuter rail stations in the Greater Toronto and Hamilton Area. Journal of Transport Geography, 68, 1-8. DOI: 10.1016/j.jtrangeo.2018.02.002.

Amiril, A. et al. (2014) Transportation Infrastructure Project Sustainability Factors and Performance. Procedia - Social and Behavioral Sciences, 153, 90-98. DOI: 10.1016/j.sbspro.2014.10.044.

Bagheri, B. \& Tousi, S. N. (2018) An explanation of urban sprawl phenomenon in Shiraz Metropolitan Area (SMA). Cities, 73, 71-90. DOI: 10.1016/j.cities.2017.10.011.

Giduthuri, V. K. (2015) Sustainable Urban Mobility : Challenges, Initiatives and Planning. 261-265.

Guerra, E. et al. (2018) Urban form , transit supply, and travel behavior in Latin America: Evidence from Mexico 's 100 largest urban areas, 69, 98-105.

Kabisch, S. (2019) Urban Transformation To Pursue Sustainability Through Resource Efficiency, Quality of Life And Resilience: A Conseptual Approach. Geographia Technica, 14, 98-107.

Liu, Z. et al. (2018) Urban sprawl among Chinese cities of different population sizes. Habitat International, 79, 89-98. DOI: 10.1016/j.habitatint.2018.08.001.

Malik, I. B. I., Suparta, W. \& Dewancker, B. J. (2019) A Study of Population Density in Developing Countries. Geographia Technica, 14, Special Issue, 201-212. DOI: 10.21163/GT_2019. 141.34.

Ministry of National Development Planning. (2018) National Urban Policy Draft. Jakarta, Indonesia. Available at: http://jakberketahanan.org/wp-content/uploads/2018/10/Paparan-Bappenas.pdf.

Motieyan, H. \& Mesgari, M. (2017) Towards Sustainable Urban Planning Through Transit-Oriented Development (A Case Study: Tehran). ISPRS International Journal of Geo-Information, 6 (12), 402. DOI: $10.3390 /$ ijgi6120402.

Pan, H. et al. (2017) What determines rail transit passenger volume? Implications for transit oriented development planning. Transportation Research Part D: Transport and Environment, 57, 52-63. DOI: 10.1016/j.trd.2017.09.016.

Soemardiono, B. et al. (2019) Spatial Analisys of Urban Dense Area in Developing Criteria Design Based on People Partisipation: Case Study of Kemban Jepun, Surabaya. Geographia Technica, 14, 13-21. DOI: 10.21163/GT_2019. 141.14.

Thomas, M., Rao, K. V. K. \& Sohoni, A. V. (2017) Application of the concept of transit oriented development to a suburban neighborhood. Transportation Research Procedia, 25, 3220-3232. DOI: $10.1016 /$ j.trpro.2017.05.135.

Thomas, R. et al. (2018) Is transit-oriented development (TOD) an internationally transferable policy concept ?. Regional Studies, 52 (9), 1201-1213. DOI: 10.1080/00343404.2018.1428740.

Wei, Y. D. \& Ewing, R. (2018) Urban expansion, sprawl and inequality. Landscape and Urban Planning, 177, 259-265. DOI: 10.1016/j.landurbplan.2018.05.021. 